\title{
Repetition is the mother of skill
}

\author{
Christopher R. Burke, MD, and Nahush A. Mokadam, MD
}

From the Division of Cardiothoracic Surgery, University of Washington, Seattle, Wash.

Disclosures: N.A.M. is a consultant for Medtronic and Abbott, and is an investigator for Medtronic, Abbott, and Syncardia. C.R.B. has nothing to disclose with regard to commercial support.

Received for publication Dec 20, 2017; accepted for publication Dec 28, 2017; available ahead of print Feb 2, 2018.

Address for reprints: Nahush A. Mokadam, MD, Division of Cardiothoracic Surgery, University of Washington, 1959 NE Pacific St, Box 356310, Seattle, WA 98195 (E-mail: mokadamn@uw.edu).

J Thorac Cardiovasc Surg 2018;155:1694-5

$0022-5223 / \$ 36.00$

Copyright (C) 2018 by The American Association for Thoracic Surgery

https://doi.org/10.1016/j.jtcvs.2017.12.096

Changing norms in surgical education and resulting work hour restrictions, along with a shift toward increased public scrutiny of outcomes, has transformed surgical training in the past decade. Trainees today are often limited in both their overall case volume during residency and realizing less autonomy within the operating room. Gone are the days of a traditional surgical training "apprenticeship" paradigm of graduated responsibility in the operating room. Therefore, adjuncts to the traditional "Halsted" method of teaching have been implemented in many residency programs. Experiential learning through simulation and video aids has been widely used in a variety of fields, including the training of airline pilots, the armed forces, and athletes; it has also been shown to be an effective tool for teaching complicated cardiothoracic operations, including the use of 3-dimensional printed models to simulate a septal myectomy and complex congenital operations. ${ }^{1,2}$ Overall, interest in simulation training within the field of cardiothoracic surgery has increased dramatically in the past decade. This has led to the development of a standardized cardiothoracic surgery simulation curriculum that has been validated to show a significant benefit in both resident performance and perceived comfort level with components of various operations. ${ }^{3-5}$

In this issue of the Journal, Malas and colleagues ${ }^{6}$ present a compelling case for the use of visualization multimedia in teaching surgical residents to perform a vascular anastomosis. They present an intriguing randomized trial that once again illuminates the beneficial effects of simulation training in cardiothoracic surgery and specifically on the use of visual experiential learning. Surgical trainees randomized to undergo anastomotic training with the use of visualization multimedia performed significantly better than their peers who received expert-guided simulation training alone. It is also interesting to note that a greater benefit was noted among more senior residents, perhaps illuminating the additive impact of both operative experience and simulation training in acquisition of complex surgical skills.

Adjuncts to traditional operative experience must be used to obtain even mere competency among graduating surgical

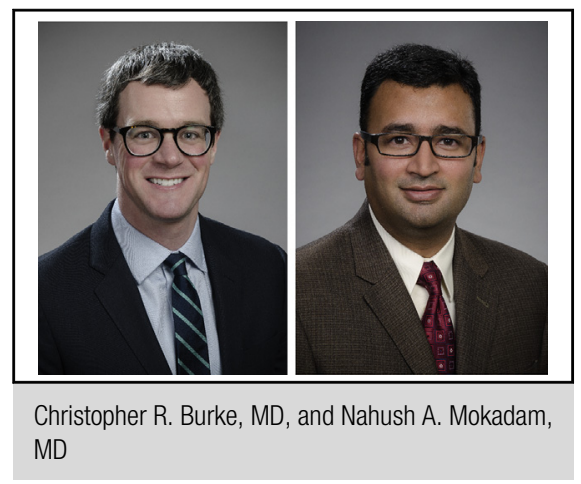

\section{Central Message}

Simulation-based training, such as visualization multimedia, provides a safe and effective environment for resident education. More investment is justified within this field.

See Article page 1686.

residents. Despite a wealth of literature in both cardiothoracic surgery and other surgical fields supporting the use of simulation-based training, these programs remain largely unfunded at most training sites. Increasing the fidelity of simulation is of paramount importance, as Malas and colleagues ${ }^{6}$ have shown by exploring the use of visualization training for teaching vascular anastomosis. As public scrutiny over surgical outcomes increases, one can easily imagine a time in the near future when simulation-based testing is part of the credentialing and certification process for surgeons. The field of simulation is likely to receive a tremendous advance in the near future as virtual reality and artificial intelligence technologies continue to be refined. Virtual reality simulators have been shown to be beneficial for teaching thoracoscopic lobectomy and components of cardiac surgery. ${ }^{7,8}$ Cardiothoracic surgery residency programs must continue to embrace, explore, and invest in simulation curricula in an effort to adequately train residents in an ever-changing and complex field. The need for simulation-based training in cardiothoracic residency is clear, and the data are robust to justify its use; therefore, the responsibility falls on educators within the field to advocate on behalf of trainees for increased investment in these programs.

\section{References}

1. Hermsen JL, Burke TM, Seslar SP, Owens DS, Ripley BA, Mokadam NA, et al. Scan, plan, print, practice, perform: Development and use of a patient-specific 3-dimensional printed model in adult cardiac surgery. J Thorac Cardiovasc Surg. 2017;153:132-40. 
2. Yoo SJ, Spray T, Austin EH, Yun TJ, van Arsdell GS. Hands-on surgical training of congenital heart surgery using 3-dimensional print models. J Thorac Cardiovasc Surg. 2017; 153:1530-40.

3. Mokadam NA, Fann JI, Hicks GL, Nesbitt JC, Burkhart HM, Conte JV, et al Experience with the cardiac surgery simulation curriculum: results of the resident and faculty survey. Ann Thorac Surg. 2017;103:322-8.

4. Feins RH, Burkhart HM, Conte JV, Coore DN, Fann JI, Hicks GL, et al. Simulation-based training in cardiac surgery. Ann Thorac Surg. 2017;103: 312-21.

5. Moorjani N, Lewis M, Shah R, Barnard S, Graham T, Rathinam S. Implementation of a novel portfolio of structured, curriculum-aligned, simulation-based, cardiothoracic surgery training courses: Evolving the delivery of surgical education. J Thorac Cardiovasc Surg. 2017;154:2009-16.

6. Malas T, Al-Atassi T, Brandys T, Naik V, Lapierre H, Lam BK. Impact of visualization on simulation training for vascular anastomosis. J Thorac Cardiovasc Surg. 2018;155:1686-93.

7. Solomon B, Bizekis C, Dellis SL, Donington JS, Oliker A, Balsam LB, et al Simulating video-assisted thoracoscopic lobectomy: a virtual reality cognitive task simulation. J Thorac Cardiovasc Surg. 2011;141:249-55.

8. Valdis M, Chu MWA, Schlachta C, Kiaii B. Evaluation of robotic cardiac surgery simulation training: a randomized controlled trial. J Thorac Cardiovasc Surg. 2016;151:1498-505. 